\title{
Nasal Cavity and Ethmoid Sinus Cancer pT4a TNM Finding v6
}

National Cancer Institute

\section{Source}

National Cancer Institute. Nasal Cavity and Ethmoid Sinus Cancer pT 4a TNM Finding v6. NCI Thesaurus. Code C65054.

Nasal cavity and ethmoid sinus cancer with tumor invading any of the following: anterior orbital contents, skin of nose or cheek, minimal extension to anterior cranial fossa, pterygoid plates, sphenoid or frontal sinuses. (from AJCC 6th Ed.) 